\title{
Erratum to: Endoplasmic Reticulum Stress Signals in Defined Human Embryonic Stem Cell Lines and Culture Conditions
}

\author{
Miguel Angel Blanco-Gelaz • Beatriz Suarez-Alvarez • Gertrudis Ligero • \\ Laura Sanchez $\cdot$ Jose Ramon Vidal-Castiñeira $\cdot$ Eliecer Coto $\cdot$ Harry Moore • \\ Pablo Menendez • Carlos Lopez-Larrea
}

Published online: 3 December 2010

(C) Springer Science+Business Media, LLC 2011

\section{Erratum to: Stem Cell Rev and Rep \\ DOI 10.1007/s12015-010-9135-4}

The online version of the original article can be found at http://dx.doi.
org/10.1007/s12015-010-9135-4.

M. A. Blanco-Gelaz • B. Suarez-Alvarez · J. R. Vidal-Castiñeira •

C. Lopez-Larrea $(\bowtie)$

Histocompatibility and Transplantation Unit,

Hospital Universitario Central de Asturias,

33006, Oviedo, Spain

e-mail: inmuno@hca.es

G. Ligero $\cdot$ L. Sanchez $\cdot$ P. Menendez

Andalusian Stem Cell Bank, Instituto de Investigacion Biomedica,

University of Granada,

Granada, Spain

E. Coto

Department of Molecular Genetics,

Hospital Universitario Central de Asturias,

Oviedo, Spain

H. Moore

Centre for Stem Cell Biology, University of Sheffield,

Western Bank,

Sheffield, UK

E. Coto $\cdot$ C. Lopez-Larrea

Red de Investigacion Renal-REDinREN,

Instituto de Salud "Carlos III",

Madrid, Spain

E. Coto $\cdot$ C. Lopez-Larrea

Fundacion Renal "Inigo Alvarez de Toledo",

Madrid, Spain
The originally published reference list of this article unfortunately contained mistakes.

Incorrect references:

16. Cortes, J. L., Sanchez, L., Ligero, G., Gutierrez-Aranda, I., Catalina, P., Elosua, C., et al. (2009). Mesenchymal stem cells facilitate the derivation of human embryonic stem cells from cryopreserved poor-quality embryos. Human Reproduction, 24, 1854-1851.

30. Garcia-Castro, J., Trigueros, C., Madreras, J., PérezSimón, J. A., Rodriguez, R., \& Menendez, P. (2008). Mesenchymal stem cells and their use as cell replacement therapy and disease modelling tool. Journal of Cellular and Molecular Medicine, 12, 1-14.

Correct references:

16. Cortes, J. L., Sanchez, L., Ligero, G., Gutierrez-Aranda, I., Catalina, P., Elosua, C., et al. (2009). Mesenchymal stem cells facilitate the derivation of human embryonic stem cells from cryopreserved poor-quality embryos. Human Reproduction, 24, 1844-1851.

30. Garcia-Castro, J., Trigueros, C., Madreras, J., PérezSimón, J. A., Rodriguez, R., \& Menendez, P. (2008). Mesenchymal stem cells and their use as cell replacement therapy and disease modelling tool. Journal of Cellular and Molecular Medicine, 12, 2552-2565. 